\title{
Applicability of thin-walled structures for energy- savings in steel construction
}

\author{
Natalia D. Korsun ${ }^{1, *}$, Daria A. Prostakishina ${ }^{1}$ \\ ${ }^{1}$ Industrial University of Tyumen, Department of Building structures, 625000 Volodarsky str., 38, \\ Tyumen, Russia
}

\begin{abstract}
The paper discusses the use of lightweight thin-walled structures which make it possible to save resources in steel construction. The highlighted challenges that this industry face in the Russian Federation involve insufficient development of the domestic standards. A thin-walled sigma-profile element with $300 \mathrm{~mm}$ in a section height has been studied. The element, its design diagram and loading have been chosen taking into account the structural performance of the columns and girders involved in CFS frameworks. The paper presents analysis technique for a thin-walled profile which performs under axial compression and axial bending compression. The structures have been calculated taking into account their main feature - the initial geometric imperfections. The analysis of the changed effective characteristics and stresses in the cross-section has revealed the significant influence of the initial geometric imperfections of the profiles and location of the extra eccentricity against the element's initial curvatures. The elastic-plastic behaviour of material occurs when the stresses in the full cross-section achieve $0.71 R_{y}$ ignoring the initial geometric imperfections, and $0.58 R_{y}-$ with regard to them. The paper substantiates the need to consider unevenness of the mechanical properties of steel distributed over the cross-section of the profile. Based on the experimental data obtained, conclusions have been drawn on the necessary adaptation of the indirect method for evaluating the strength characteristics of thin-walled samples.
\end{abstract}

\section{Introduction}

At present, rational consumption of non-renewable energy resources is challenging. Thus, energy efficiency and energy-savings are the priorities for technological development of the Russian economy. The urgency of the study is also due to the inefficiency of the state economy, i.e. energy intensity of the gross domestic product (GDP). It is shown in the Energy Savings and Energy Efficiency Program of the Russian Federation for the period until 2020 as 2.5 times higher than the average world level. This Program aims at reducing energy consumption by at least 40 percent until 2020 .

The construction industry is an active consumer of energy resources; therefore, in accordance with the Federal Law "On Energy Savings and Energy Efficiency Improvement"

${ }^{*}$ Corresponding author: korsunnd@tyuiu.ru 
high priority measures aim at technical control of energy consumption in this sector of economy. The Energy Savings Program is a set of measures aimed at reducing energy consumption at all stages of the building life cycle. These measures include development of effective design and technical solutions and life support systems, use of alternative energy sources, improvement of the rules and regulations, as well as a number of other resourcesaving measures.

When analyzing this issue, we can conclude that great attention is being paid to thermal protection of buildings and energy efficiency increase [1, 2, 3, 4, 11], i.e. rational energy consumption through development and implementation of various heat-insulating materials, energy-efficient translucent structures and facade systems [5, 12-14]. It is necessary to point out the rationality of this approach, since the losses of heat energy through the building enclosure are as follows: through the walls - 30-49\%, windows - $25-35 \%$, basement and attic floors - $10-18 \%$ depending on the number of storeys in a building, its life and enclosure material [6]. However, energy savings is another way to reduce energy consumption, i.e. to reduce energy costs by economical use of fuel and energy resources.

Applicability of less resource-demanding structures and the most efficient production technology is one of the ways to reduce energy consumption in the construction industry. The paper will discuss applicability of lightweight thin-walled structures (CFS) to reduce energy consumption in steel construction.

CFS are structures manufactured from cold-rolled sheet steel $(0.6 \div 3 \mathrm{~mm})$ by cold bending on rolling mills with subsequent galvanizing [8-10, 15-19]. They are an effective alternative to traditional hot-rolled profiles in the case when the use of the latter is irrational. Application of CFS in construction is the most industrialized and easily managed process, since they are prefabricated structures. The structures erected from CFS are lightweight frameworks which are interconnected into a spatial system. The connected profiles are the most frequently used as the main load-bearing members of the framework. They are interconnected in a symmetrical section with bolts, self-tapping screws, and rivets.

The energy-efficient technology is advantageous due to the following:

1. Low specific weight of the framework results in reduction of energy consumption for its production. This factor makes it possible to significantly reduce the load on the foundation being erected, and hence the cost of its construction is also reduced.

2. Speed of erection procedure. Quite fast assembly of the framework reduces the time and labour costs for site erection works; besides, the CFS technology let you do without lifting mechanisms, which is effective in new construction or reconstruction in the cramped conditions of urban development.

3. Lack of "wet processes". This factor makes it possible not to take into account the seasonality of construction and perform site erection works throughout a year.

Besides, the advantages of the energy-efficient technology include its environmental friendliness, variety of architectural forms and cost savings in interior finishing.

In order to demonstrate possible resource savings, let us compare the specific metal content of the mass-produced one-storeyed channel frameworks and brace frameworks made from industrial steel structures and CFS depending on the vertical loading. The following parameters have been taken as the initial dimensions of the framework: span - $18 \mathrm{~m}$, length $60 \mathrm{~m}$, height of the truss bottom - $6 \mathrm{~m}$. The following industrial steel structures/CFS framework types have been compared: industrial steel structures - Orsk of Orsk Steelwork Plant; Kansk of Kansk Light Steelwork Plant; Molodechno of Molodechno Steelwork Plant; UNITECH of UNICON, Research and Design Bureau, Kemerovo; CFS -UNITEX-R1 of UNICON, Research and Design Bureau, Kemerovo (Fig. 1). 


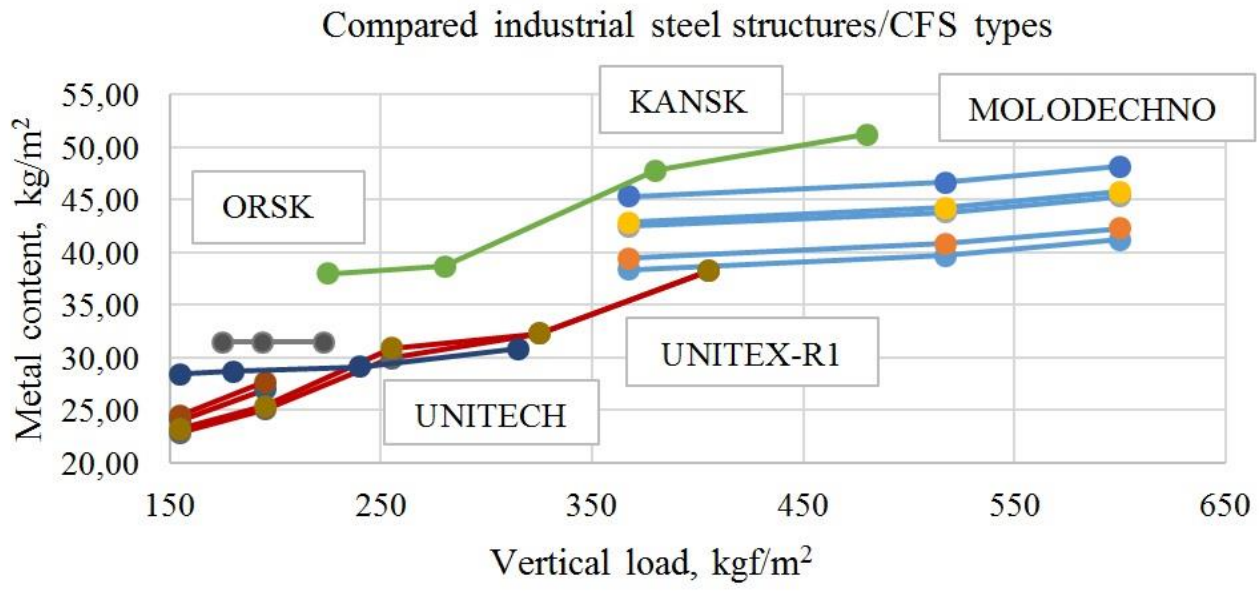

Fig. 1. Specific consumption of metal per mass-produced frameworks versus vertical loading.

Based on the dependencies obtained, it can be concluded that UNITEX-R1 and UNITECH frameworks are the most effective, however, it should be noted that the CFS framework is the most effective in low loading (up to 50\%). In accordance with the series 1.420.3-39.08: Steel Frameworks UNITEX-R1, delivery 0-1, the framework is capable of taking larger loads than the industrial steel structures framework produced according to the series 1.420.3-36.03: Steel Frameworks of UNITECH type. Thus, applicability of CFS structures in steel construction is substantiated as a necessary measure that ensures energy savings in this industry.

\section{Analysis}

However, applicability of thin-walled structures in the domestic construction industry is challenging due to the lack of the developed domestic rules and regulations concerning the design standards of CFS members. The Code Specification for Steel Thin-walled Structures (SP 260.1325800.2016) "Steel Thin-walled Structures" was introduced in 2016 on the basis of the European Standard EN1993-1-3:2006. To evaluate the actual behaviour of structures, it recommends taking into account experimental data obtained, but this requires extra costs for designing.

Specific features for the calculated thin-walled profiles are determined by a number of significant factors:

- loss of local stability of individual sections in the compressed zone,

- loss of stability of the sectional shape,

- loss of overall stability of the element,

- initial geometric imperfections,

- uneven distribution of mechanical properties over the cross-section.

Geometric imperfections arise due to elastic and elastic-plastic deformations which appear in manufacturing the profile by cold rolling. The values of the initial geometric imperfections of thin-walled profiles are recommended to be assigned depending on the accuracy class of their manufacture based on GOST 23188-2012 "Building steel structures. General technical standards". For CFS profiles, the accuracy class should be at least equal to 5. Despite the fact that the necessary consideration of the initial geometric imperfections is specified in the standards, the relevant technique is absent.

The need to take into account uneven distribution of mechanical properties over the cross section arises due to the specific technology used for manufacturing thin-walled cold-bent 
elements. The manufacturing procedure for these structures is as follows: coil steel is cut into longitudinal profile-like strips, and then the strips are installed in the machine. A cold bending technique is used between rolls. Bending in the desired profile is carried out by sequentially arranged pairs of rollers (rolls); their number depends on the complexity of the profile. A cold-hardening zone is formed in bending sections in cold bending of metals.

The Code Specification SP 260.1325800.2016 regulates evaluation of the standard and design resistances of steel on the basis of statistical processing using minimum distribution values. However, when calculating, it is possible to take into account variability of the mechanical properties of steel over the bent profile section. This is obtained from the experimental data due to steel hardening in the zones of cold bending. There is not any analytical method to take into account the uneven distribution of mechanical properties over the cross-section of the profile. In 2015 Kosykh P.A. studied thin-walled profiles made from steel-08ps in Perm NIPU. The studies showed that the yield strength and temporal resistance values were significantly larger compared to the standard values [7] (Table 1), which confirms the need to take into account the influence of this factor when calculating the stressstrain state of the element.

Table 1. Compared standard values of mechanical properties of steel-08ps and experimental data obtained.

\begin{tabular}{|c|c|c|}
\hline Mechanical parameter & GOST 1050-2013 & Tested \\
\hline Yield strength, $\mathrm{MPa}$ & 196 & 440 \\
\hline Temporal resistance, $\mathrm{MPa}$ & 320 & 620 \\
\hline
\end{tabular}

Thus, it is possible to substantiate the need to study the effect of the initial geometric imperfections of profiles on the stress-strain state of the thin-walled element, as well as uneven distribution of the changed mechanical properties of steel, which is determined by laboratory analysis on particular section zones.

The element and its design diagram are chosen with regard to structural performance of the columns and girders in the CFS frameworks as members subjected to the effect of the longitudinal compressive force and bending moment in the plane of the transverse frame and braced from the plane by connected elements. Loading is due to the similar factors characteristic of the structural behaviour of the frame elements in the braced framework of the building. An element of two connected sigma-profiles, $300 \mathrm{~mm}$ in cross-section height (Fig. 2), has been taken to study; its geometric characteristics are presented in Table 2. The element length is $\mathrm{L}=15 \mathrm{~h}=4500 \mathrm{~mm}$. It is made of steel-350 in accordance with GOST R 52246-2016 "Hot-galvanized sheet metal. Technical standards". The design diagram of the element is given in Fig.3. Hinged fastening in the moment plane has been made at the ends of the element, and $1500 \mathrm{~mm}$ - from the moment plane.
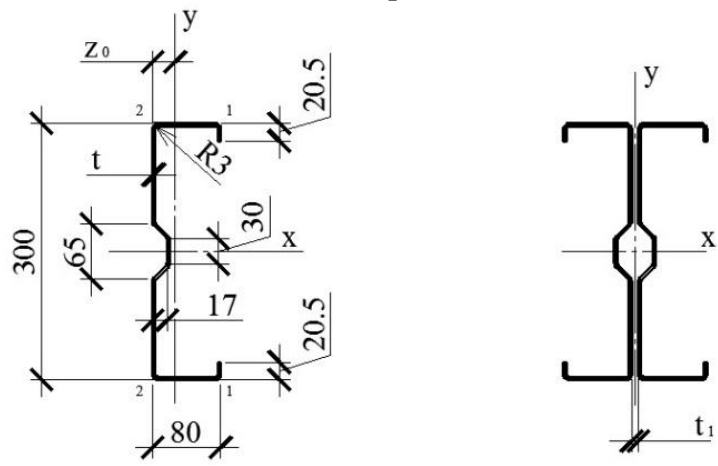

Fig. 2. Geometric dimensions of the sigma-profile and schematic illustration of the connected section. 


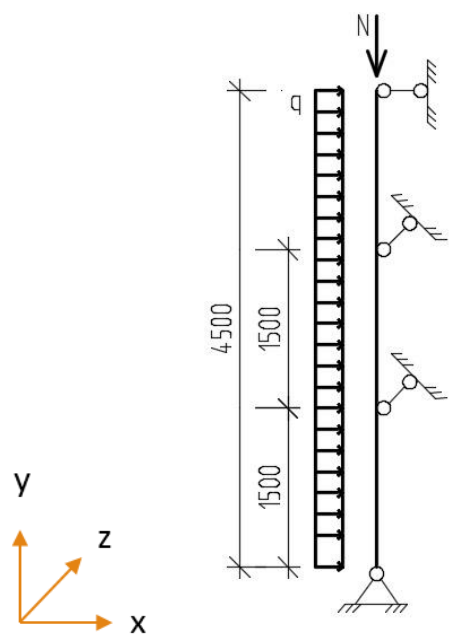

Fig. 3. Design diagram of the element under study.

Table 2. Geometric characteristics of the full cross-section.

\begin{tabular}{|c|c|c|c|c|}
\hline $\mathrm{A}, \mathrm{cm}^{2}$ & $\mathrm{~W}_{\mathrm{y}}, \mathrm{cm}^{3}$ & $\mathrm{~W}_{\mathrm{x}}, \mathrm{cm}^{3}$ & $\mathrm{I}_{\mathrm{y}}, \mathrm{cm}^{4}$ & $\mathrm{I}_{\mathrm{x}}, \mathrm{cm}^{4}$ \\
\hline 20.03 & 28.36 & 167.34 & 226.88 & 2510.05 \\
\hline
\end{tabular}

The analysis technique for thin-walled structures is based on application of an effective cross-sectional area and provides for replacement of cross-sectional zones with individual plates being anchored in different ways. Accordingly, geometric characteristics of the compressed sectional zones are replaced by the reduced ones taking into account the loss of local stability; the effective and full geometric characteristics coincide for stretched sectional zones. The thickness and width of the plate in the reduced zones of the cross section change when calculating by multiplying the initial thickness by the reduction factor $\rho$, which depends on the ratio of stresses in the cross-sectional element, its flexibility, boundary conditions of plate anchoring and loss of stability. It is assumed that the spring stiffness is endless for the edge stiffening member that supports the flange, and it is similar for the part of the sectional zone with the intermediate stiffening member. When the reduction factor is determined, subsequent iterations are performed; in here, stiffness of the effective cross-sectional braces and the load-bearing capacity reduction factor $\chi_{d, n}$ are determined; the compressive stress decreases in subsequent iterations, taking into account the load-bearing capacity reduction factor until the following condition is met:

$$
X_{\mathrm{d}, \mathrm{n}} \approx X_{\mathrm{d},(\mathrm{n}-1)}, X_{\mathrm{d}, \mathrm{n}} \leq X_{\mathrm{d},(\mathrm{n}-1)}
$$

The value of initial geometric imperfections of the profiles has been taken into account according to the Code Specification - SP 260.1325800.2016 for local imperfections because of the following formula:

$$
e_{0} / L=1 / 250
$$

and for general imperfections - in accordance with GOST 23188-2012 for the $5^{\text {th }}$ accuracy class of elements.

Since the initial imperfections cannot be controlled numerically and directionally, but they can create extra eccentricity of the applied longitudinal compressive force, it is necessary 
to specify the maximum possible value of eccentricity for the given length of the rod. In order to consider the initial geometrical imperfections, let us determine the straightness differences for an element of $4.5 \mathrm{~m}$ in length, the $5^{\text {th }}$ accuracy class (Fig.4). The maximum possible curvatures are $30 \mathrm{~mm}$.

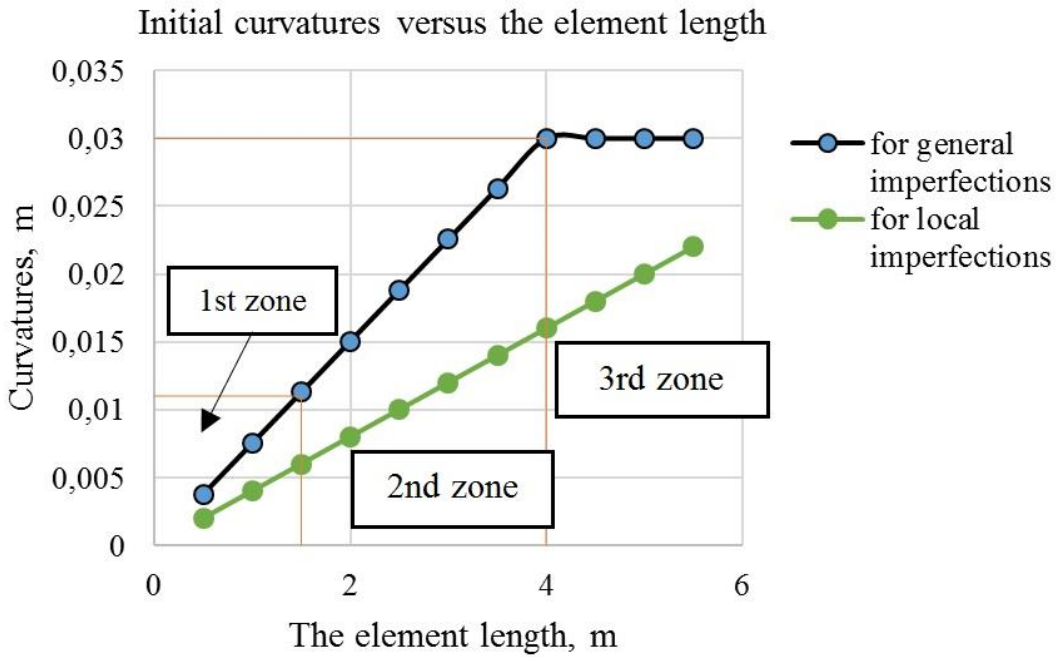

Fig. 4. Initial curvatures versus the element length.

In order to determine the effect of the initial geometric imperfections and longitudinal bending on the stress-strain state of the rod composed of the symmetric sigma-profile sections, three loading cases have been considered:

- element's behaviour under axial compression,

- element's behaviour under bending compression (eccentric compression) ignoring its initial geometric imperfections,

- element's behaviour under bending compression (eccentric compression) taking into account its initial geometric imperfections.

\subsection{Case of axial compression}

One branch has been calculated, since the stresses at each point of the cross-section are equal. The reduced characteristics are similar for the second branch. The calculating procedure for the effective characteristics of the element is as follows:

- the effective cross-section of the element is determined taking into account the loss of local stability and presence of the edge stiffening members; it is assumed that with $\mathrm{K}=\infty$, $\sigma_{\text {com }}=R_{\mathrm{y}}$ for the edge stiffening member which strengthens the compressed flange;

- the critical stress of the loss of stability is determined for the plate in the elastic stage $\sigma_{\mathrm{cr}, \mathrm{s}}$;

- the load-bearing capacity reduction factor $\chi_{\mathrm{d}}$ due to the loss of stability of the crosssectional shape of the elements is determined using the effective cross-section and supporting members;

- the effective thickness of the element with the reduced area is determined;

- subsequent iterations; repeating the calculation procedure all over again. Calculation of an effective width with the reduced compressive stress is performed, $\sigma_{\mathrm{com}}=X_{\mathrm{d}} R_{\mathrm{y}}$, using $X_{\mathrm{d}}$ from the previous iteration. 


\subsection{Case of bending compression (eccentric compression)}

Let us determine the reduced parameters of the cross-section under bending compression ignoring the initial geometric imperfections: for compressed flanges - similar to the case of central compression, taking into account that the maximum stress in the flanges is equal to the yield strength of steel $\sigma_{\max }=R_{\mathrm{y}}$; the effective characteristics of the stretched flanges correspond to the full ones. The reduction coefficient is determined from the ratios of compressive and tensile stresses for a cross-sectional element with an intermediate stiffening member (Fig.5).

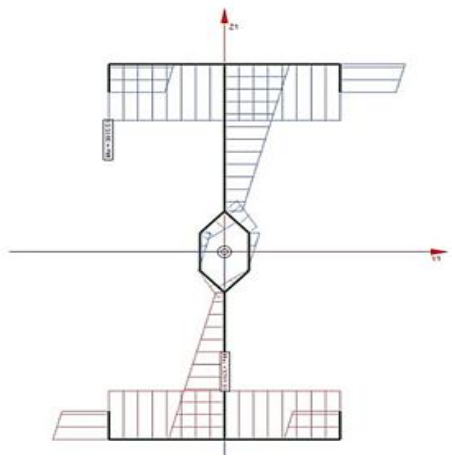

Fig. 5. Schematic illustration of stress distribution over the element cross-section under bending compression ignoring the initial geometric imperfections.

\subsection{Case of bending compression taking into account the initial geometric imperfections}

A number of cases of possible eccentricity have been studied taking into account the initial imperfections of the element which compresses eccentrically; the study has revealed two characteristic cases and proper stress distribution over the cross-section depending on the longitudinal compressive force applied (Fig. 6):

Case 1 - displacement of the longitudinal force along the axis $y$ by $30 \mathrm{~mm}$ without angular displacement;

Case 2 - displacement of the longitudinal force along the axis $x$ with angular displacement by \pm 45 degrees.
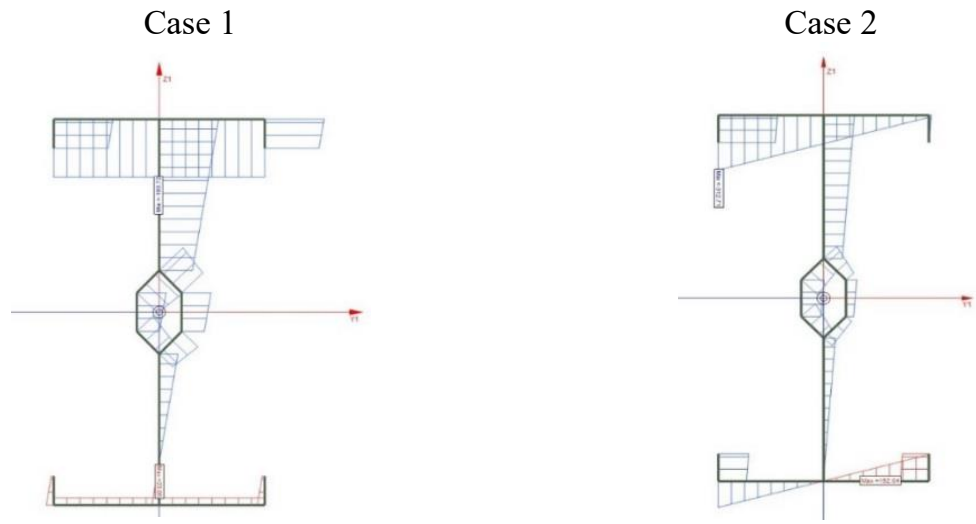

Fig. 6. Stress distribution over the cross-section under bending compression taking into account the initial geometric imperfections 
This loading case is characterized by extra stresses in the cross-section which occur due to the extra forces $\Delta M_{x} и \Delta M_{y}$, resulting from extra eccentricities equal to the distance between the respective axes of the full and effective cross-sections.

\subsection{Considered uneven distribution of mechanical properties of thin-walled elements}

The experimental zones for assessing the strength characteristics have been chosen on the basis of the studies on distribution of the mechanical properties of steel over the cross-section and profile thickness carried out by Soviet scientists in the 20th century. The following characteristic zones in the sigma-profile cross-section have been distinguished based on the theoretical data obtained: 1) in bending sections at an angle of $90^{\circ} ; 2$ ) in bending sections at an angle of $\left.136^{\circ} ; 3\right)$ zones adjacent to the corner zones of $90^{\circ}$ at a distance of up to $6 \mathrm{t} ; 4$ ) straight sections on the profile flanges; 5) zones adjacent to the corner zones of $136^{\circ}$ at a distance of up to $6 \mathrm{t}$; 6) zones adjacent to the corner zones of $136^{\circ}$ at a distance from $6 \mathrm{t}$ to $12 \mathrm{t}$; 7) zones adjacent to the corner zones of $136^{\circ}$ located on the intermediate stiffening member; 8) straight sections of the profile web (Fig.7).

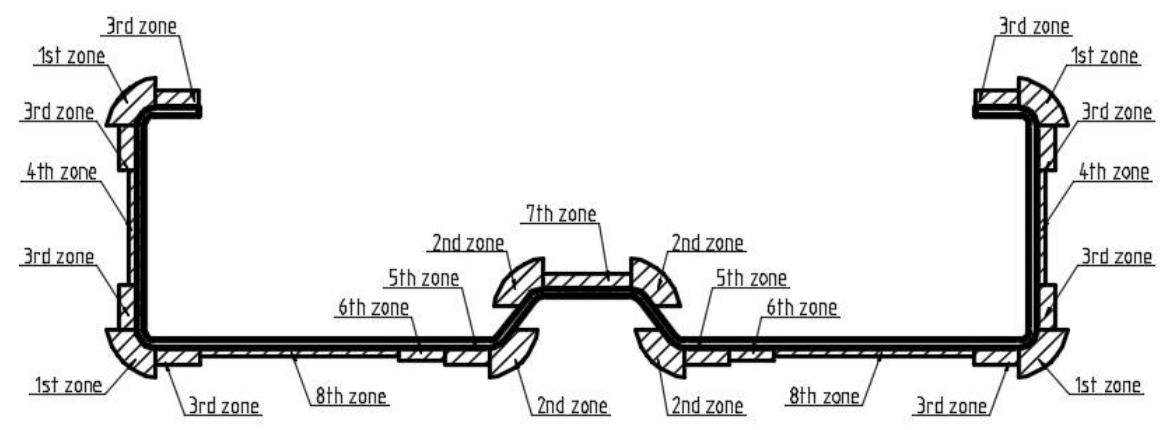

Fig. 7. Characteristic zones of the cross-section to take into account mechanical properties of the material.

\section{Results}

The effective cross-section of the profile in the case of axial compression is shown in Fig.8; the effective characteristics of the cross-section are presented in Table 3.

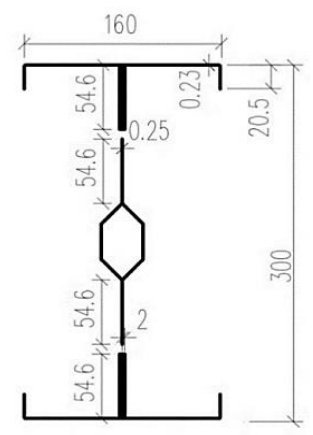

Fig. 8. Effective cross-section of the element in axial compression. 
Table 3. Geometric characteristics of the effective cross-section in axial compression.

\begin{tabular}{|c|c|c|c|c|}
\hline$A, \mathrm{~cm}^{2}$ & $W_{y}, \mathrm{~cm}^{3}$ & $W_{\mathrm{x}}, \mathrm{cm}^{3}$ & $I_{\mathrm{y}}, \mathrm{cm}^{4}$ & $I_{\mathrm{x}}, \mathrm{cm}^{4}$ \\
\hline 6.7 & 3.79 & 59.96 & 30.34 & 899.37 \\
\hline
\end{tabular}

The effective geometric characteristics of the cross-section under bending compression are shown in Fig.9 and Table 4.

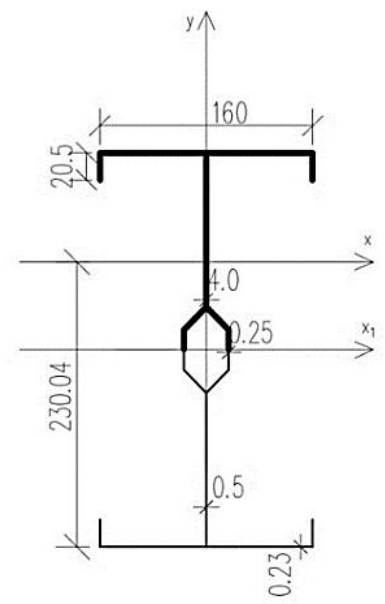

Fig.9. Effective element cross-section under bending compression ignoring the initial geometric imperfections.

Table 4. Geometric characteristics of the effective cross-section under bending compression ignoring the initial geometric imperfections.

\begin{tabular}{|l|l|l|l|l|}
\hline$A, \mathrm{~cm}^{2}$ & $W_{y}, \mathrm{~cm}^{3}$ & $W_{x}, \mathrm{~cm}^{3}$ & $I_{y}, \mathrm{~cm}^{4}$ & $I_{x}, \mathrm{~cm}^{4}$ \\
\hline 11.63 & 17.93 & 32.70 & 143.42 & 753.25 \\
\hline
\end{tabular}

The calculated geometric characteristics of the cross-section under bending compression, taking into account the initial imperfections in accordance with Cases 1 and 2, are presented in Fig. 10 and Table 5.

Case 1

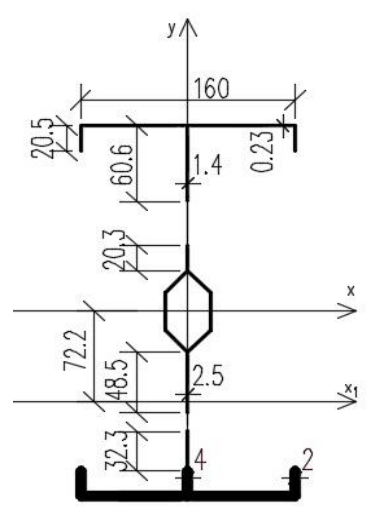

Case 2

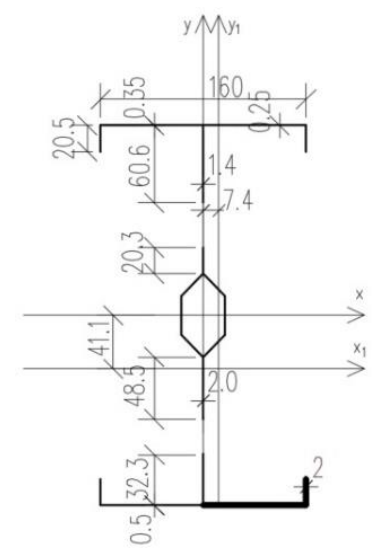

Fig. 10. Effective element cross-section under bending compression taking into account the initial geometric imperfections. 
Table 5. Geometric characteristics of the effective cross-section under bending compression taking into account the initial geometric imperfections.

\begin{tabular}{|c|c|c|c|c|c|}
\hline Case & $A, \mathrm{~cm}^{2}$ & $W_{y}, \mathrm{~cm}^{3}$ & $W_{x}, \mathrm{~cm}^{3}$ & $I_{y}, \mathrm{~cm}^{4}$ & $I_{x}, \mathrm{~cm}^{4}$ \\
\hline 1 & 9.84 & 17.78 & 42.45 & 142.24 & 943.22 \\
\hline 2 & 8.75 & 9.73 & 48.54 & 93.15 & 958.27 \\
\hline
\end{tabular}

When analyzing the effective geometric characteristics, one can draw the conclusion that the case of axial compression is the case of the smallest effective cross-sectional area $\left(\mathrm{A}_{\text {red }}\right.$ $=6.7 \mathrm{~cm}^{2}$, which is $0.33 \mathrm{~A}$ ), since all the plates are characterized by local loss of stability, the effective cross-sectional area increases under eccentric compression taking into account the initial geometric imperfections or ignoring them; however, axial compression is an idealized example of structural performance of the element. Therefore, it is unpractical to rely on the parameters of its structural performance under axial compression.

The cross-sectional area decreases in the cases of eccentric compression taking into account the initial geometric imperfections of the profiles as compared with the case that does not take into account the initial geometric imperfections - by 15 and $24 \%$ respectively for cases 1 and 2. This is due to the increased compressed cross-sectional area where the section moment increases in relation to the horizontal axis (displacement of the centroidal axis of the effective cross- section towards the stretched one) and decreases in relation to the vertical axis. The maximum stresses in the effective cross-section are observed for case 2 taking into account the initial geometric imperfections in the plane perpendicular to the bending plane.

The stresses calculated for the effective cross-section under bending compression ignoring the initial geometric imperfections have shown that the stresses increase due to the loss of local stability by individual cross-sectional members; in here, the elastic-plastic behaviour of the material occurs when the stresses in the full cross-section reach $0.71 R_{y}$.

When taking into account the initial imperfections, the material passes into the zone of elastic-plastic behaviour at stresses in full cross-section equal to $0.58 R_{y}$. The increased stresses are related to the appeared extra forces $\Delta M_{x}$ and $\Delta M_{y}$.

Direct and indirect methods have been used to determine mechanical properties on a few samples; the experiment has resulted in an increased temporal resistance in the zone of greatest strengthening by $10 \%$ as compared to straight low-strengthened sections, i.e. $17 \%$ increase as compared to the standard values. However, it has been concluded that the indirect method is not perfect for thin-walled samples and it needs to be adapted. Thus, it is possible to further study this topic.

\section{Conclusions}

In accordance with the Code Specification SP 294.1325800.2017 "Steel structures. Design rules" and GOST R 52246-2016 for steel-350 with an ultimate stress limit of 475-485 N/mm² and a yield strength of $390-400 \mathrm{~N} / \mathrm{mm}^{2}$, the ratio is $\sigma_{u} / \sigma_{y}=1.2<1.3$. Therefore, development of inelastic deformations and transition to the stage of self-strengthening in the stretched zone is not allowed for this element, but inelastic deformations are taken into account in compressed zones, and this ensures full utilization of the material and its properties. The graphical representation of stress distribution across the cross-section (Fig.6) makes it possible to conclude that the stretched zone continues its work in the elastic stage, as opposed to the compressed zone; this agrees with p. 4.4 of the Code Specification SP 294.1325800.2017 and makes it possible to analyze the supercritical behaviour of the element, but the reserve of such behaviour may be lost due to the initial imperfections of the element. 


\section{References}

1. Y. Cheng, J. Nin, N. Gao, Building and Environment 47, 13-22 (2012) 10.1016/j.buildenv.2011.05.011

2. H. Orr, J. Wang, D. Fetsch, R. Dumont, Journal of Building Physics 36, 294-307 (2013) 10.1177/1744259112460748

3. P. Rohdin, A. Molin, B. Moshfegh, Building and Environment 71, 176-185 (2014)

4. A. Dodoo, L. Gustavsson, R. Sathre, Energy and Buildings 43-7, 1566-1572 (2011) 10.1016/j.enbuild.2011.02.019

5. A.V. Orlova, E.N. Zhmarin, K.O. Paramonov, I.J. Construction of Unique Buildings and Structures 11-6, 1-13 (2013)

6. A.S. Vladimirova, R.G. Abakumova, International Scientific Journal "Innovation Science" 3, 145-147 (2017)

7. P.A. Kosykh, Bulletin of TGASU 2, 135-143 (2015)

8. B.W. Schafer, Journal of Constructional Steel Research 64, 766-778 (2008) 10.1016/j.jcsr.2008.01.022

9. Y.B. Kwon, Journal of Constructional Steel Research 65, 278-289 (2009) 10.1016/j.jcsr.2008.07.005

10. S. Mohebbi, Thin-Walled Structures 91, 50-62 (2015) 10.1016/j.tws.2015.02.00702638231

11. A.S. Gorshkov, N.I. Vatin, P.P. Rymkevich, O.O. Kydrevich, Magazine of Civil Engineering 78, 65-75 (2018) doi:10.18720/MCE.78.5

12. M.R. Petritchenko, E.V. Kotov, D.V. Nemova, D.S. Tarasova, V.V. Sergeev, Magazine of Civil Engineering 77, 130-140 (2018) doi:10.18720/MCE.77.12

13. M.R. Petrichenko, D.V. Nemova, E.V. Kotov, D.S. Tarasova, V.V. Sergeev, Magazine of Civil Engineering 77, 47-58 (2018) doi:10.18720/MCE.77.5

14. M.R. Petritchenko, S.A. Subbotina, F.F. Khairutdinova, E.V. Reich, D.V. Nemova, V.Y. Olshevskiy, V.V. Sergeev, Magazine of Civil Engineering 73, 40-48 (2017) doi:10.18720/MCE.73.4

15. N. Vatin, A. Sinelnikov, M. Garifullin, D. Trubina, Applied Mechanics and Materials 633-634, 1037-1041 (2014) doi:10.4028/www.scientific.net/AMM.633-634.1037

16. A.A. Kikot, Magazine of Civil Engineering 61, 42-59 (2016) doi:10.5862/MCE.61.5

17. A.D. Pavlenko, V.A. Rybakov, A.V. Pikht, E.S. Mikhailov, Magazine of Civil Engineering 67, 55-69 (2016) doi:10.5862/MCE.67.6

18. V.A. Rybakov, M. Al Ali, A.P. Panteleev, K.A. Fedotova, A.V. Smirnov, Magazine of Civil Engineering 76, 28-39 (2017) doi:10.18720/MCE.76.3

19. I.S. Vedishcheva, M.Y. Ananin, M. Al Ali, N.I. Vatin, Magazine of Civil Engineering 78, 116-127 (2018) doi:10.18720/MCE.78.9 